\title{
Conservative Management of a Patient with an Arach- noid Cyst of the Cerebellopontine Angle
}

Athanasios Konstantelias ${ }^{1^{*}}$, Antonios Sakellaropoulos ${ }^{2}$ and Sofia Mourgela ${ }^{1}$

${ }^{1}$ Department of Neurosurgery, "Agios Savvas" Oncological Hospital, Athens, Greece

${ }^{2}$ Pulmonary medical center, Athens, Greece

'Correspondence to:

Athanasios Konstantelias, MD

Department of Neurosurgery

"Agios Savvas" Oncological Hospital

35 Katsimpa Street, 17342, Agios Dimitrios

Athens, Greece

Tel: +306981223593

E-mail: a.a.konstantelias@gmail.com

Received: March 09, 2018

Accepted: March 09, 2018

Published: March 11, 2018

Citation: Konstantelias A, Sakellaropoulos A, Mourgela S. 2018. Conservative Management of a Patient with an Arachnoid Cyst of the Cerebellopontine Angle. J Neuroimaging Psychiatry Neurol 3(1): 12.

Copyright: (C) 2018 Konstantelias et al. This is an Open Access article distributed under the terms of the Creative Commons Attribution 4.0 International License (CC-BY) (http:// creativecommons.org/licenses/by/4.0/) which permits commercial use, including reproduction, adaptation, and distribution of the article provided the original author and source are credited.

Published by United Scientific Group

\section{Dear Editor,}

We have read with great interest the review article published in Journal of Neuroimaging in Psychiatry \& Neurology by Logan et al. [1]. The authors reported that the treatment options for patients with arachnoid cysts are still under debate. Additionally, the literature in the conservative treatment of patients with arachnoid cysts who have neurological symptoms is considered limited. We would like to share our experience with a male patient who presented with vertigo. The patient reported that vertigo did not affect the quality of his life. He did not mention a traumatic injury or other health problems. Further assessment with a Magnetic Resonance Imaging (MRI) of the brain revealed an arachnoid cyst of the right cerebellopontine angle (Figure 1). The medical examination of the patient showed gait ataxia. We attributed the clinical presentation of the patient to the presence of the arachnoid cyst. Non-operative, observational management was preferred. Three years later the patient reported that the sensation of vertigo had disappeared entirely. Ataxia was absent as well. The MRI follow-up of the brain (Figure 2) demonstrated a reduction in the size of the arachnoid cyst. The patient is still under close follow-up with MRI of the brain. Further studies are needed to examine whether a non-surgical, observational approach in patients with mild clinical symptoms attributed to an arachnoid cyst should be beneficial.

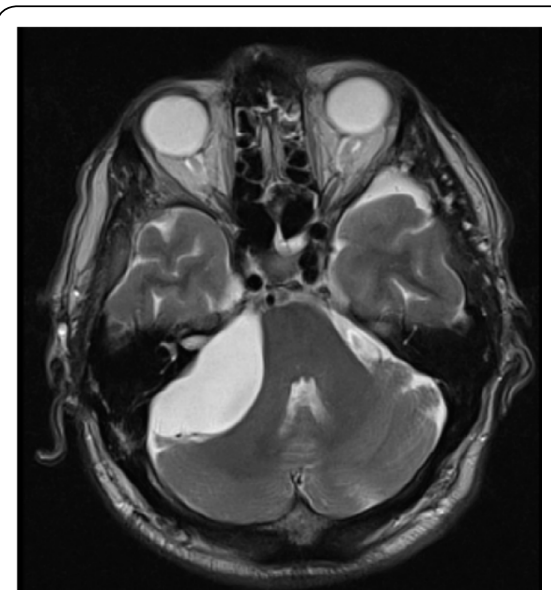

Figure 1: Initial T2-weighted MRI of the brain showing an arachnoid cyst of the right cerebellopontine angle.

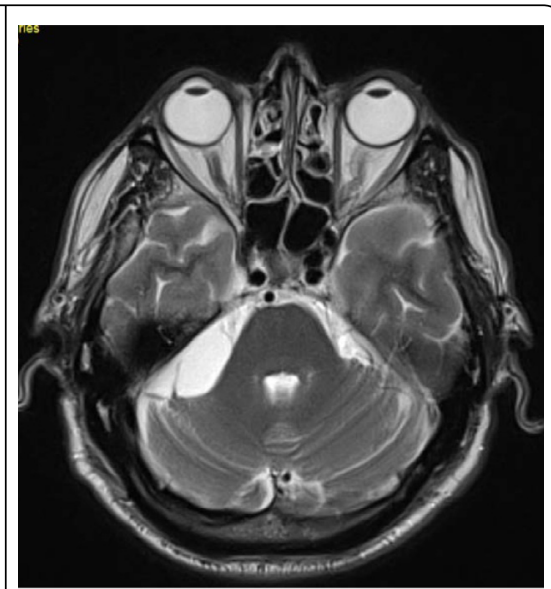

Figure 2: Follow-up T2-weighted MRI of the brain after three years showed a reduced size of the arachnoid cyst.

\section{Conflict of Interest}

There is no conflict of interest pertaining to this manuscript.

\section{References}

1. Logan C, Asadi H, Kok HK, Looby S, O'Hare A, et al. 2016. Arachnoid cysts - common and uncommon clinical presentations and radiological features. J Neuroimaging Psychiatry Neurol 1(2): 79-84. https://doi.org/10.17756/jnpn.2016-010 